Tropical Journal of Pharmaceutical Research April 2020; 19 (4): 873-878

ISSN: $1596-5996$ (print); 1596-9827 (electronic)

(C) Pharmacotherapy Group, Faculty of Pharmacy, University of Benin, Benin City, 300001 Nigeria.

\title{
Knowledge, attitude and practice of Lebanese community pharmacists with regard to self-management of low back pain
}

\author{
Mariam K Dabbous ${ }^{1 *}$, Sara M Moustafa1, Fouad R Sakr ${ }^{1}$, Marwan G AKel ${ }^{1-3}$, \\ Jihan H Safwan ${ }^{1}$, Michelle M Cherfan ${ }^{1}$, Mohamad K Rahal ${ }^{1}$ \\ ${ }^{1}$ School of Pharmacy, Lebanese International University, Beirut, Lebanon, ${ }^{2}$ University of Toulouse, UPS, Inserm, Toulouse, \\ ${ }^{3}$ National Institute of Public Health Clinical Epidemiology and Toxicology (INSPECT_LB), France
}

*For correspondence: Email: mariam.dabbous@liu.edu.lb; Tel: 0096-176877750

Sent for review: 16 November 2019

Revised accepted: 24 January 2020

\begin{abstract}
Purpose: To determine the knowledge, attitude and reported practice of Lebanese community pharmacists who advise persons who present with low back pain.

Methods: This was a multi-center cross-sectional study conducted in over 300 community pharmacies across Lebanon from December 2017 to May 2018. Pharmacists working at a community pharmacy were considered eligible, and those who volunteered to participate completed the questionnaire. The questionnaire was designed for self-completion by the pharmacist and included demographic questions about the respondent, questions that assessed knowledge and attitude toward low back pain, and questions about treatment to reflect and characterize the nature of practice. The primary outcome was to determine the knowledge, attitude and reported practice of the Lebanese pharmacists advising people who presented with low back pain. The secondary outcome was to assess factors that affect knowledge, attitude, and practice.

Results: The response of 320 community pharmacists was analysed. The proportion of pharmacists with good knowledge about low back pain (51. $7 \%$ ) was slightly higher than those with poor knowledge (48. $3 \%)$. Oral therapy was the most prescribed dosage form for back pain compared to local patch and cream. Among oral dosage forms, non-steroidal anti-inflammatory drugs were the most prescribed medications (42\%). Of the patients' referral to the physician if necessary, $73.1 \%$ of the referrals were by pharmacists.

Conclusion: Community pharmacists in Lebanon demonstrate an acceptable level of knowledge of back pain, yet major gaps still exist, particularly in terms of the quality of advice. Hence, more education is needed to provide better quality of advice.
\end{abstract}

Keywords: Attitude, Knowledge, Low back pain, Reported practice, Quality of advice

This is an Open Access article that uses a fund-ing model which does not charge readers or their institutions for access and distributed under the terms of the Creative Commons Attribution License (http://creativecommons.org/licenses/by/4.0) and the Budapest Open Access Initiative (http://www.budapestopenaccessinitiative.org/read), which permit unrestricted use, distribution, and reproduction in any medium, provided the original work is properly credited.

Tropical Journal of Pharmaceutical Research is indexed by Science Citation Index (SciSearch), Scopus, International Pharmaceutical Abstract, Chemical Abstracts, Embase, Index Copernicus, EBSCO, African Index Medicus, JournalSeek, Journal Citation Reports/Science Edition, Directory of Open Access Journals (DOAJ), African Journal Online, Bioline International, Open-J-Gate and Pharmacy Abstracts

\section{INTRODUCTION}

Low back pain (LBP) is a very common disorder that affects 80 percent of people at some point in their life. It is one of the most common causes that leads to job-related disability and missed work days [1]. According to the Global Burden of Disease 2010 study, LBP ranked highest in terms of disability (YLDs), and sixth in terms of overall burden (DALYs) [2]. Attitudes and beliefs 
toward low back pain impacts its severity and extent of disability. Evidence-based treatment for low back pain includes: brief educational intervention, short-term painkillers, supervised exercise and counseling. To maximize the chance of successful treatment, it is important that all healthcare professionals understand that an active management is the best strategy as recommended by the guideline [3].

In Lebanon, community pharmacists can be consulted for advice and to support guidance given by other healthcare professionals without an appointment. Furthermore, many of the treatments used for LBP are considered OTC and can be purchased from the community pharmacist without a prescription. Many patients with LBP presenting first to the physician will subsequently present to the pharmacy with a prescription, making pharmacists in a perfect position to give appropriate advice and support guidance given by other healthcare professionals [3]. Beyond dispensing OTC medications and giving appropriate information and advice, pharmacists refer patients to a physician when necessary. Therefore, pharmacists are well positioned to provide evidence-based advice on LBP and contribute to patient's health outcomes and quality of life [2].

Very few studies have evaluated the knowledge, attitude, and belief of the pharmacist toward LBP. Yet, some evidence suggests that such factors might influence health care professional recommendations. For example, some surveys have shown that physicians have gaps in knowledge and negative beliefs toward low back pain ${ }^{[4]}$. Such gaps were proven by reports that showed: one-quarter of acute LBP is referred for imaging despite evidence that this can delay recovery [5]. Evidence-based guideline recommends staying active, avoiding bed rest and the use of simple analgesics [6]. However, surveys showed that such steps are ignored, prolonging improvement and increasing the costs on society [7-8].

An over-cautious attitude toward LBP among healthcare professionals may result in the wrong management of this condition. However, positive attitude and belief among healthcare professionals are associated in providing evidence-based advice and management to the patient $[4,9]$. In the literature, there is little precise information about the quality of care provided in the community pharmacy to patients presenting with back pain; hence, the aim of this study was to investigate pharmacists' knowledge, attitude, and practice toward low back pain. Findings from this study will provide important information about pharmacists' knowledge, attitude, and practice toward LBP and identify gaps which need to be addressed.

\section{METHODS}

\section{Study design}

This was a multi-center cross sectional study conducted between January and June 2018 in Lebanese community pharmacies. The institutional review board of the Lebanese International University approved the study protocol and amendments. An oral consent was obtained from the respondents.

\section{Study population}

This cross-sectional study was carried out using a proportionate random sample of the Lebanese community pharmacies from all districts of Lebanon. A complete list of community pharmacies was obtained from the Order of Pharmacists. A sample of 300 pharmacists was targeted 10 percent of the community pharmacies in Lebanon. Hence, 400 questionnaires were distributed to allow for the refusals and exclusions. The questionnaires were distributed to pharmacies randomly. Pharmacists working at the community pharmacy were considered eligible. The pharmacist had the choice to accept or refuse to fill the questionnaire. At the end of the process, the questionnaires were collected and returned.

\section{Study protocol}

After a thorough review of related literature, a data collection sheet with close-ended questions was designed in English language for selfcompletion by the pharmacist. The questionnaire was organized into six sections:

- Demographic questions about the respondent

- Questions that reflected knowledge about low back pain

- Questions about attitudes and beliefs toward low back pain

- Questions about the treatment of back pain in the community pharmacy to reflect and characterize the nature of practice

- Questions about when to refer

- Questions about pharmacists role and if education and trainings are needed

\section{Study outcomes}

The primary outcome of this study was to determine knowledge, attitude and reported 
practice of Lebanese community pharmacists advising patients who present with acute or chronic low back pain to the community pharmacy. The secondary outcome was to assess demographic factors that affect pharmacist knowledge.

\section{Statistical analysis}

Data were analysed using the Statistical package of the Social Science (SPSS) version 22.0. Qualitative variables were presented as frequency and percentage, while quantitative variables were presented as means and standard deviations (SDs). A bivariate analysis was conducted to assess factors related to knowledge, attitude and practice using Pearsonchi square test.

A logistic regression was then performed to identify sociodemographic factors that are independently associated with the following dependent variables knowledge, attitude and practice, reported as odds ratios (ORs) and $95 \%$ confidence interval $(\mathrm{Cl}) . P<0.05$ was considered statistically significant.

The score for knowledge was obtained by first assigning one point for the right answer and no point each of the 7 questions on knowledge. After that, the points for each pharmacist were added up to give the pharmacist a score. Then the median for all score which was 5 was then obtained. All pharmacists who obtained a score of 5 and above were considered to have good knowledge, while all pharmacists who scored $<5$ were considered to have poor knowledge. The score for referral was obtained in the same way.

\section{RESULTS}

\section{Pharmacist characteristics}

A total of 346 filled questionnaires were collected from the pharmacies. Out of the 346 who were enrolled, 320 were included while 26 were excluded either because they still didn't earn their Bachelor of pharmacy degree or didn't answer the question "Did you earn a BS pharmacy degree?" Consequently, complete data was collected and analyzed from 320 community pharmacists.

\section{Demographic characteristics}

From the total number of pharmacists enrolled ( $\mathrm{n}$ $=320$ ), the results showed that females in this study where slightly more than the males; 179 $(53.4 \%)$ versus 149 (46.6\%). As for the age categories, many of the pharmacists were middle aged. The age category above 60 was underrepresented in our study (4.2\%). Enrolled pharmacists had a mean age of $38.17 \pm 11.088$ (Mean years \pm Standard deviation SD). Postgraduate studies were classified into 6 categories. Half the pharmacists in this study did not do any post graduate study $(50.5 \%)$, while the other half $(49.5 \%)$ where distributed between the different postgraduate studies.

The pharmacist position at the pharmacy was grouped into three categories with the majority being the owner $58.9 \%$ while the others were distributed between full-time or part-time employees. Years of experience was grouped into 5 categories, with the highest percentage for 5 - 10 years $(30.6 \%)$ while the lowest percentage for 16 - 20 years of experience (13.8 $\%)$. Hours of practice was grouped into 4 categories, with the highest percentage for 8 - 24 $\mathrm{h}$ of practice per week (46.6\%) while the lowest percentage was for 25 - $40 \mathrm{~h}$ per week (11.6 \%).

\section{Pharmacists' knowledge of low back pain}

Most of the pharmacists $(90.9 \%)$ stated that low back pain is not always related to injury, $78.3 \%$ answered that low back pain can be described as aching, burning stabbing, tingling, dull or sharp, $60.6 \%$ agreed that back pain usually gets worse before it gets better and finally $93.3 \%$ agreed that patients should avoid all painful movements (Table 1). Only $20.7 \%$, disagreed that a patient with back pain should rest until it gets better and $38.8 \%$, agreed that a patient with back pain should try to stay active which identify major gap in pharmacists' knowledge about nonpharmacological management of low back pain. Finally, $43.8 \%$ disagreed that if you have back pain you should not return to work until you are free of pain (Table 2).

Overall, Lebanese community pharmacists' knowledge on low back pain was acceptable with $51.7 \%$ having good knowledge while $48.3 \%$ having poor knowledge. When controlling for other factors, years of experience and hours of practice seem to affect knowledge. Pharmacists with more years of experience and more hours of practice per week seem to demonstrate better knowledge (Odds ratio [OR] equal 0.146 and 4 . $603 ; p=0.020$ and 0.007 respectively Table 3 .

\section{Frequency of advice regarding back pain}

Forty six percent of the pharmacists are asked more than 16 times per week about low back pain advice, $43 \%$ are asked 6 - 15 times per week about low back pain advice while only $11 \%$ 
said that they were asked 1 - 5 times per week about low back pain advice.

\section{Pharmacists' attitude toward low back pain}

$8.2 \%$ have negative feelings about advising people with back pain, $46.6 \%$ frequently refer people with back pain to their general physician,
$81.4 \%$ consider back pain as an important topic where they work, $91.1 \%$ agreed that where they work they are often asked about advice for back pain, $98.1 \%$ agreed that they offer good advice about back pain and finally $95.2 \%$ agreed that their support staff offers good advice about back pain (Table 4).

Table 1: Pharmacists' knowledge of low back pain

\begin{tabular}{lcc}
\hline Item & True & False \\
& $\mathbf{N}(\%)$ & $\mathbf{N}(\%)$ \\
\hline LBP is always related to injury? & $29(9.1)$ & $291(90.9)$ \\
LBP can be described as aching, burning, stabbing, tingling, dull or sharp? & $246(78.3)$ & $68(21.7)$ \\
Back pain usually gets worse before it gets better? & $189(60.6)$ & $123(39.4)$ \\
Patients should avoid all painful movement? & $292(93.3)$ & $21(6.7)$ \\
\hline
\end{tabular}

Table 2: Pharmacists knowledge on low back pain

\begin{tabular}{lccccc}
\hline & $\begin{array}{c}\text { Strongly } \\
\text { disagree } \\
\mathbf{N ~ ( \% )}\end{array}$ & $\begin{array}{c}\text { Disagree } \\
\mathbf{N}(\%)\end{array}$ & $\begin{array}{c}\text { Neutral } \\
\mathbf{N}(\%)\end{array}$ & $\begin{array}{c}\text { Agree } \\
\mathbf{N}(\%)\end{array}$ & $\begin{array}{c}\text { Strongly } \\
\text { agree } \\
\mathbf{N}(\%)\end{array}$ \\
\hline $\begin{array}{l}\text { Item } \\
\begin{array}{l}\text { If you have back pain you should rest } \\
\text { If you have back pain you should try }\end{array}\end{array}$ & $10(3.2)$ & $55(17.5)$ & $5(1.6)$ & $195(61.9)$ & $50(15.9)$ \\
$\begin{array}{l}\text { and stay active? } \\
\text { If you have back pain you should not } \\
\text { return to work until you are free of pain? }\end{array}$ & $61(19.4)$ & $110(35)$ & $22(7)$ & $109(34.7)$ & $12(3.8)$ \\
\hline
\end{tabular}

Table 3: Factors that affect pharmacists' knowledge

\begin{tabular}{|c|c|c|c|}
\hline Independent variable & ORa & $95 \% \mathrm{Cl}$ & $P$-value \\
\hline \multicolumn{4}{|l|}{ Age } \\
\hline \multicolumn{2}{|l|}{29 years and below } & $0.703-3.578$ & 0.267 \\
\hline 40 years and above & 1.914 & $0.530-6.903$ & 0.321 \\
\hline \multicolumn{4}{|l|}{ Gender } \\
\hline Female & 1.351 & $0.755-2.415$ & 0.311 \\
\hline \multicolumn{4}{|c|}{ Did you conduct any post-graduate studies? } \\
\hline PharmD & 0.735 & 0.383-1.409 & 0.353 \\
\hline Diploma & 2.298 & $0.461-11.472$ & 0.310 \\
\hline Master & 1.901 & $0.808-4.469$ & 0.141 \\
\hline $\mathrm{PhD}$ & 0.315 & $0.059-1.680$ & 0.176 \\
\hline Others & 0.340 & $0.033-3.547$ & 0.367 \\
\hline \multicolumn{4}{|l|}{ Area of residence } \\
\hline \multicolumn{4}{|l|}{ Beirut } \\
\hline Others & 0.610 & $0.324-1.149$ & 0.126 \\
\hline \multicolumn{4}{|c|}{$\begin{array}{l}\text { How would you describe your current position at the pharmacy? } \\
\text { Owner }\end{array}$} \\
\hline Employer & 0.925 & $0.454-1.883$ & 0.830 \\
\hline \multicolumn{4}{|l|}{ Years of experience } \\
\hline $5-10$ years & 0.608 & $0.240-1.543$ & 0.295 \\
\hline $11-15$ years & 0.396 & $0.127-1.229$ & 0.109 \\
\hline $16-20$ years & 0.298 & $0.066-1.347$ & 0.116 \\
\hline$>20$ years & 0.146 & $0.029-0.743$ & 0.020 \\
\hline \multicolumn{4}{|l|}{$\begin{array}{l}\text { Hours of practice } \\
<6 \mathrm{~h}\end{array}$} \\
\hline $8-24 \mathrm{~h}$ & 3.561 & $1.271-9.978$ & 0.016 \\
\hline $25-40 \mathrm{~h}$ & 3.285 & $0.977-11.046$ & 0.055 \\
\hline$>40 \mathrm{~h}$ & 4.603 & $1.513-14.002$ & 0.007 \\
\hline
\end{tabular}


Table 4: Lebanese Pharmacists' attitude and beliefs toward low back pain

\begin{tabular}{|c|c|c|}
\hline Item & $\begin{array}{c}\text { Disagree } \\
\mathbf{N}(\%) \\
\end{array}$ & $\begin{array}{l}\text { Agree } \\
\text { N (\%) }\end{array}$ \\
\hline I often have negative feelings about advising people with back pain & $290(91.8)$ & $26(8.2)$ \\
\hline I most frequently refer people with back pain to their GP & 164(53.4) & 143(46.6) \\
\hline Back pain is an important topic where I work & $59(18.6)$ & $258(81.4)$ \\
\hline Where I work people often ask for advice about back pain & $28(8.9)$ & $285(91.1)$ \\
\hline I offer good advice about back pain & $6(1.9)$ & $310(98.1)$ \\
\hline My support staff offers good advice about back pain & $15(4.8)$ & $300(95.2)$ \\
\hline
\end{tabular}

Table 5: Pharmacist role in low back pain management

\begin{tabular}{|c|c|c|c|c|c|}
\hline Item & $\begin{array}{c}\text { Strongly } \\
\text { Disagree } \\
\mathbf{N}(\%)\end{array}$ & $\begin{array}{c}\text { Disagree } \\
\mathbf{N}(\%)\end{array}$ & $\begin{array}{c}\text { Neutral } \\
\mathbf{N}(\%)\end{array}$ & $\begin{array}{l}\text { Agree } \\
\mathbf{N}(\%)\end{array}$ & $\begin{array}{c}\text { Strongly } \\
\text { Agree } \\
\mathbf{N}(\%) \\
\end{array}$ \\
\hline $\begin{array}{l}\text { Pharmacist should be the first health } \\
\text { care member of call for patients with LBP }\end{array}$ & $7(2.2)$ & $70(21.9)$ & $13(4.1)$ & $173(54.1)$ & $57(17.8)$ \\
\hline $\begin{array}{l}\text { Pharmacists have an important role to } \\
\text { play in helping patients with LBP }\end{array}$ & $0(0)$ & $2(0.6)$ & $4(1.31)$ & $83(57.2)$ & $131(40.9)$ \\
\hline $\begin{array}{l}\text { Pharmacists are a very useful source of } \\
\text { advice on medicines for LBP } \\
\text { Do you think we need educational }\end{array}$ & $0(0)$ & $6(1.9)$ & $5(1.6)$ & $138(43.1)$ & $171(53.4)$ \\
\hline programs on LBP management & $5(1.6)$ & $3(4.1)$ & 23(7.2) & $164(51.3)$ & $115(35.9)$ \\
\hline
\end{tabular}

\section{Reported practice}

Most of patients were prescribed oral therapy for low back pain (58\%); between the medications prescribed for low back pain. NSAIDs were the most prescribed medication (42 \%), where diclofenac $50 \mathrm{mg}$ was the most prescribed NSAID. Between the combinations, diclofenac with vitamin B12 was the most prescribed. Most of the pharmacists $(73.10 \%)$ referred low back pain patients that seem to be caused by an underlying serious disease.

Pharmacist's role in low back pain management

Around $71.9 \%$ agreed that pharmacists should be the first health care member of call for patients with low back pain, $98.1 \%$ agreed that pharmacists have an important role to play in helping patients with low back pain, $96.5 \%$ agreed that pharmacists are a useful source of advice on medicines for low back pain, and finally $87.2 \%$ agreed that educational programs about low back pain management is needed (Table 5).

\section{DISCUSSION}

The study was conducted to understand the nature and various advice and practice that patients with low back pain are likely to receive in the Lebanese community pharmacy. It is a step to determine, describe and document pharmacists in everyday practice. By this means, it enhances our knowledge about Lebanese pharmacists' care of patients with low back pain.
This study has identified gaps in practice with regards to non-pharmacological advice for low back pain, particularly around advice to stay active and avoid prolonged periods of bed rest which highlight the need for on-going education and training for Lebanese community pharmacists about low back pain to ensure evidence-based information is implemented. The gaps in knowledge of Lebanese community pharmacists about low back pain showed by this survey were higher than the results of a similar survey done in England but lower than one done in Australia [10,11]. Evidence-based guidelines recommend staying active and avoiding prolonged periods of bed rest, however surveys of practice overseas have shown that these steps are often ignored increasing health risk to consumers and costs to society $[7,8]$.

An over-cautious attitude towards low back pain among healthcare professionals may result in the inappropriate management of this condition. Conversely positive attitude and beliefs among healthcare are associated with successful implementation of guideline recommendation $[12,13]$. Results from this study showed that Lebanese community pharmacists seem to have a positive attitude toward low back pain management since the majority disagreed that they have negative feelings about low back pain and agreed that they and their staff offer good advice.

The American college of physicians (ACP) issued an updated clinical practice for the management of acute and subacute low back 
pain which recommends appropriate exclusion of a serious cause, the reassurance of a favorable prognosis, the need to remain active, avoid periods of bed rest and treatment with non-drug therapies such as superficial heat, massage, acupuncture or spinal manipulation. If drug therapy is desired, NSAIDs or skeletal muscle relaxants must be chosen as the first line [6]. Evidence suggests that pain relief does not differ between traditional OTC NSAIDs and prescription NSAIDs [14].

Most of the evidence available on healthcare professional's management of low back pain are from self-report questionnaires or respondents clinical vignettes $[12,15,16]$. Only few, studies have evaluated what happens in practice by direct observation, but these studies did not compare practice with the overall care prescribed in low back pain management $[16,17]$. Rather, these studies evaluated questions commonly asked by pharmacists and non-pharmacist staff and medicine's information provided. There is limited evidence from a self-report questionnaire that pharmacist recommendations regarding pharmacological management of acute low back pain are consistent with guideline recommendations. However, this evidence comes from pharmacists who participated in the recruitment of participants for a low back pain clinical trial and who had received training on low back pain management, hence this event may not be broadly representative [16].

This study has shown that recommendations of pharmacological management for low back pain provided by Lebanese community pharmacists are typically aligned with clinical practice guidelines. The oral dosage form was the most prescribed dosage form with NSAIDs being the most often prescribed medication. Between the NSAIDs, diclofenac was the most often prescribed. This conforms to findings from a simulated patient study conducted in Malaysia which showed that diclofenac was the most commonly supplied medication for acute back pain [18].

Referral to a specialist or imaging is only indicated when there is suspected fracture or signs and symptoms of a red flag. Findings from this study oppose previous research which has identified a need to educate and train pharmacists and non-pharmacist staffs in identifying and referring a red flag, as up to $73.4 \%$ of the pharmacists in this study were capable of identifying the medical emergency and providing medical referral [19]. But still educating pharmacists on the appropriate use of imaging and need for prompt referral would also help to ensure that accurate and reliable information is provided to patients presenting with symptoms of low back pain.

This study has identified gaps in practice in regard to non-pharmacological advice for low back pain, particularly around advice to stay active and avoid prolonged periods of bed rest. A consumer health survey conducted in the USA showed that less than a third of those who tried an OTC medicine for their back pain reported it was very helpful [20]. This reinforces the need to counsel on non-pharmacological therapies with known benefits such as exercise, as this may have a synergistic effect. However, interventions targeting community pharmacists commonly consulted by low back pain patients can serve an important role in aligning practice with evidencebased practice guidelines.

Many studies have investigated interventions designed to change health care professional behaviour in the management of low back pain $[20,21]$. A two-hour workshop on low back pain management in Australia targeting community pharmacists has led to a favorable change in pharmacists' knowledge, attitudes and beliefs towards LBP so that it more closely aligned with evidence-based guidelines [16]. Finally, nearly all the pharmacists in this study agreed that educational programs are needed in order to improve practice.

The major strength of this study is that it is a multicenter study done in all districts of Lebanon, with a representative number of the Lebanese community pharmacists $(n=320)$.

\section{Limitations of the study}

One of the limitations was the difficulty in finding similar studies for comparison. There might also be an information bias because pharmacists questioned may not have been completely honest. Moreover, the questionnaire used was not a validated questionnaire that might have caused a response bias.

\section{CONCLUSION}

Pharmacological recommendations provided by Lebanese community pharmacists typically align with clinical practice for low back pain, while nonpharmacological advice does not. Participation in educational workshop might help provide community pharmacists with evidence-based knowledge about low back pain management to improve practice and the information provided for the patients. 


\section{DECLARATIONS}

\section{Conflict of interest}

No conflict of interest is associated with this work.

\section{Contribution of authors}

We declare that this work was done by the authors named in this article and all liabilities pertaining to claims relating to the content of this article will be borne by the authors.

\section{Open Access}

This is an Open Access article that uses a funding model which does not charge readers or their institutions for access and distributed under the terms of the Creative Commons Attribution License (http://creativecommons.org/licenses/by/ 4.0) and the Budapest Open Access Initiative (http://www.budapestopenaccessinitiative.org/rea d), which permit unrestricted use, distribution, and reproduction in any medium, provided the original work is properly credited.

\section{REFERENCES}

1. Low Back Pain Fact Sheet National Institute of Neurological Disorders and Stroke [Internet]. [cited 2018 Mar 11]. Available from: https://www.ninds.nih.gov/ Disorders/Patient-Caregiver-Education/Fact-

Sheets/Low-Back-Pain-Fact-Sheet

2. Hoy $D$, March L, Brooks $P$, Blyth $F$, Woolf A, Bain C, Williams G, Smith E, Vos T, Barendregt J, et al. The global burden of low back pain: estimates from the Global Burden of Disease 2010 study. Ann Rheum Dis 2014; 73(6): 968-974.

3. Silcock J, Moffett JK, Edmondson H, Waddell G, Burton AK. Do community pharmacists have the attitudes and knowledge to support evidence based self-management of low back pain? BMC Musculoskelet Disord 2007; 8: 10.

4. Buchbinder $R$, Staples $M$, Jolley $D$. Doctors With a Special Interest in Back Pain Have Poorer Knowledge About How to Treat Back Pain. Spine 2009; 34(11): 1218-1226.

5. Williams CM, Maher CG, Hancock MJ, McAuley JH, McLachlan AJ, Britt H, Fahridin S, Harrison C, Latimer J. Low Back Pain and Best Practice Care: A Survey of General Practice Physicians. Arch Intern Med 2010; 170(3): 271-277.

6. American College of Physicians issues guideline for treating nonradicular low back pain | ACP Newsroom | ACP [Internet]. [cited 2018 Jun 27]. Available from: https://www.acponline.org/acp-newsroom/american- college-of-physicians-issues-guideline-for-treatingnonradicular-low-back-pain

7. GonzálezUrzelai V, PalacioElua L, LópezdeMunain J. Routine primary care management of acute low back pain: adherence to clinical guidelines. Eur Spine $\mathrm{J}$ 2003;12(6):589-594.

8. Wilk V, Palmer HD, Stosic RG, McLachlan AJ. Evidence and Practice in the Self-Management of Low Back Pain: Findings From an Australian Internet-based Survey: Clin J Pain 2010; 26(6):533-540.

9. Houben RMA, Gijsen $A P$, Peterson J, Jong $P J$ de, Vlaeyen JWS. Do health care providers' attitudes towards back pain predict their treatment recommendations? Differential predictive validity of implicit and explicit attitude measures. Pain 2005; 114(3): 491-498.

10. Henschke N, Maher CG, Refshauge KM, Herbert RD, Cumming RG, Bleasel J, York J, Das A, McAuley JH. Characteristics of Patients With Acute Low Back Pain Presenting to Primary Care in Australia. Clin J Pain 2009; 25(1):5-11.

11. Karnath B. Clinical Signs of Low Back Pain. Hosp Physician 2003; 5:39-56.

12. Shaheed CA, Maher CG, Mak W, Williams KA, McLachlan AJ. The effects of educational interventions on pharmacists' knowledge, attitudes and beliefs towards low back pain. Int $\mathrm{J}$ Clin Pharm 2015;37(4):616-625.

13. Low Back Pain and Best Practice Care: A Survey of General Practice Physicians | JAMA Internal Medicine | JAMA Network [Internet]. [cited 2018 Apr 1]. Available from: https://jamanetwork.com/journals/jamainternalme dicine/fullarticle/415588

14. The Community Pharmacist's Role In Managing Lower Back Pain [Internet]. [cited 2018 Jun 27]. Available from: http://bt.e-

ditionsbyfry.com/article/The+Community+Pharmacist\%E $2 \% 80 \% 99 s+R o l e+I n+$ Managing +Lower+Back+Pain/284 7983/428827/article.html

15. Qaseem A, Wilt TJ, McLean RM, Forciea MA, for the Clinical Guidelines Committee of the American College of Physicians. Noninvasive Treatments for Acute, Subacute, and Chronic Low Back Pain: A Clinical Practice Guideline From the American College of Physicians. Ann Intern Med 2017;166(7):514.

16. Shaheed CA. Optimising management of low back pain in primary care [dissertation]. [Sydney]: The University of Sydney; 2015 Jun; $p 272$.

17. Buchbinder R, Jolley $D$, Wyatt M. Population based intervention to change back pain beliefs and disability: three part evaluation. BMJ 2001; 322(7301): 1516-1520

18. Chua SS, Ramachandran CD, Paraidathathu TT. Response of community pharmacists to the presentation of back pain: a simulated patient study. Int J Pharm Pract 2010; 14(3): 171-178.

19. Shaheed CA, Maher CG, Mak W, Williams KA, McLachlan AJ. Knowledge and satisfaction of pharmacists attending an educational workshop on

Trop J Pharm Res, April 2020; 19(4):879 
evidence-based management of low back pain. Aust $\mathrm{J}$ Prim Health; 2015; 21(2): 126-131.

20. 2012 Survey of U.S. Health Care Consumers: Five-Year Look Back [Internet]. Deloitte Insights. [cited 2018 Jun 29]. Available from: https://www2.deloitte.com/insights/ us/en/industry/health-care/2012-survey-of-u-s-healthcare-consumers-five-year-look-back.html

21. Roumie CL, Griffin MR. Over-the-counter analgesics in older adults: a call for improved labelling and consumer education. Drugs Aging 2004; 21(8): 485-498. 